Check for updates

Cite this: RSC Adv., 2018, 8, 24923

Received 11th May 2018

Accepted 25th June 2018

DOI: $10.1039 / \mathrm{c} 8 \mathrm{ra04009e}$

rsc.li/rsc-advances

\section{Acetic acid lignins from Chinese quince fruit (Chaenomeles sinensis): effect of pretreatment on their structural features and antioxidant activities $\uparrow$}

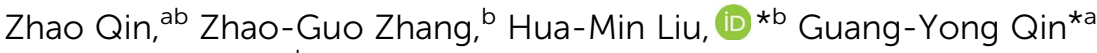 \\ and Xue-De Wang ${ }^{\text {b }}$
}

In this study, three pretreatment processes were evaluated for their effects on the structural features and antioxidant activities of lignins extracted by the acetosolv process from the fruit of Chinese quince. The three pretreatments included dephenolization, sugar removal, and multiple processes (a combination of both dephenolization and sugar removal). The results showed that after sugar removal pretreatment, the carbohydrate content, the molecular weight and S/G value of the lignin fractions decreased. However, after dephenolization pretreatment, the carbohydrate content and the molecular weight of the lignin fractions increased. After sugar removal and dephenolization, there were increases in the temperatures corresponding to the maximal rate of decomposition (DTG $G_{\text {max }}$ ) in all lignin fractions. The radical scavenging index of lignin after sugar removal pretreatment was higher compared to other pretreatments and no treatment. The results of these tests showed that sugar removal, as a pretreatment, enhanced lignin extraction, yielding pure and highly functional lignins. Additionally, dephenolization or multiple process were beneficial to the acquisition of macromolecular lignins. All the results provided references for the biorefinery of biomass rich in polyphenol and sugar compounds.

\section{Introduction}

Chaenomeles sinensis Koehne (common name: Chinese quince) is widely planted in eastern Asian countries, including China, Korea and Japan. Its fruits have been used in Chinese herbal medicine. In previous reports, the polyphenols, flavonoids and organic acids extracted from $C$. sinensis fruits have been confirmed to have antioxidant and antiulcerative activities with various health benefits. ${ }^{1-3}$ However, the lignins, which are abundant in $C$. sinensis fruits, have been little investigated in terms of structural properties and antioxidant activities.

Lignin is an amorphous phenolic polymer formed by the copolymerization of $p$-coumaryl, sinapyl and coniferyl alcohol. ${ }^{4,5}$ Lignin fractions extracted from various lignocellulosic biomasses (e.g., rice husk, sugarcane bagasse) can be used as free radical scavengers due to their high antioxidant properties. ${ }^{6}$ The major chemical functional groups in lignin can vary depending on its genetic origin and how it is isolated. The isolation process can change the native structure of lignin, even

${ }^{a}$ School of Physics and Engineering, Zhengzhou University, Zhengzhou 450001, PR China.E-mail: qinguangyong@zzu.edu.cn

${ }^{b}$ College of Food Science and Technology, College of International Education, Henan University of Technology, Zhengzhou 450001, PR China. E-mail: liuhuamin5108@ 163.com

$\dagger$ Electronic supplementary information (ESI) available. See DOI: 10.1039/c8ra04009e when the lignin belongs to the same group, as evidenced in changes in the location and number of functional groups $\left(-\mathrm{COOH},-\mathrm{CO}-,-\mathrm{OCH}_{2},-\mathrm{OH}\right){ }^{7}$ Regarding the method of isolating lignin from different biomasses, organosolv isolation is one of the most promising techniques and has attracted much attention recently. ${ }^{8}$ Although various organosolvents have been used in lignin isolation, acetic acid is primarily used because of its lower cost and greater ease of recovery. According to current literatures, no investigations have been undertaken for studying the isolation of lignin from Chinese quince by organosolvents in general, nor by acetic acid in particular.

Compared with the traditional raw materials used in the pulp and paper industries, such as hard woods, soft woods, and grasses, the fruits of Chinese quince have more phenolic and sugar compounds. Chinese quince fruit has abundant phenolic compounds (1280 mg/100 $\mathrm{g}$ of fresh weight), which is 20 times higher than that in apple $\left(61 \mathrm{mg} / 100 \mathrm{~g}\right.$ of fresh weight). ${ }^{9}$ Phenolic compounds and sugar compounds in pretreated and non-pretreated biomass have been found to have negative effects on ethanol fermentation. ${ }^{\mathbf{1 0}}$ The phenolic compounds can form complexes with proteins and inhibit cellulolytic and hemicellulolytic enzyme activities. ${ }^{\mathbf{1 1}}$ Soluble sugars also inhibit cellulases instantaneously, and it predominates other inhibitors in decreasing the initial hydrolysis rate of cellulose to glucose $;^{10}$ hence, the pretreatment of biomass through phenol and sugar compounds removal is expected to reduce enzyme loadings and therefore reduce enzyme costs for a given level of 
cellulose conversion. Moreover, both of these types of compounds have important effects on the structure and antioxidant activities of lignin during the acetosolv process. For example, Lange and Faix reported a high Klason residue and attributed it to condensation between lignin and polyphenols during the acid treatment. ${ }^{12}$ Removal of sugar compounds by hot-water pretreatment can increase the amount of free phenolic hydroxyl groups in lignin during subsequent acid extraction. ${ }^{13}$

In previous studies, the researchers explored the inhibitory effect of phenolic compounds and sugar compounds released from pretreated lignocellulose on the biomass conversion. However, until now, the effects of removing sugar and phenolic compounds on lignin structure and antioxidant properties have not been investigated. In the present investigation, ethanol organosolv pretreatment below $100{ }^{\circ} \mathrm{C}$ and liquid hot water pretreatment at atmospheric pressure were used to remove phenolic and sugar compounds before the acetic acid isolation of lignin from Chinese quince fruits. Secondly, the lignin fractions from the various samples were characterized in order to ascertain and understand any structural modifications caused by the various pretreatment processes. In addition, the antioxidant abilities of the lignin fractions were assessed because these properties are associated with potential industrial and pharmaceutical applications.

\section{Materials and methods}

\subsection{Materials}

Chinese quince (Chaenomeles sinensis) fruits were freshly harvested from Tongbai County $\left(32^{\circ} 32^{\prime} \mathrm{N}, 113^{\circ} 16^{\prime} \mathrm{E}\right)$ in Henan Province, China. The ripe fruit was sliced into layers about $2 \mathrm{~mm}$ thick and then sun-dried. The dried samples were ground to obtain 40-60 mesh particles. The powder was extracted by ethanol/toluene $(1: 2, \mathrm{v} / \mathrm{v})$ in a Soxhlet instrument, then dried at $50{ }^{\circ} \mathrm{C}$ for $10 \mathrm{~h}$. Powder obtained in this way was defined as EF (extract-free) and was used for all subsequent experiments.

\subsection{Pretreatment methods}

Different pretreatments can be used to remove different compounds from the raw Chinese quince fruit pulp. Ethanol can be used to remove phenolic compounds, while water can be used to remove sugars. In this study, we compared the effect of three types of pretreatment, namely, the removal of phenols, removal of sugars, removal of both phenols and sugars.

The method used here for removing phenolic compounds is the same as that used by previous researchers, with some modifications. ${ }^{14}$ Briefly, the EF samples (100 g) were extracted in $300 \mathrm{~mL} \mathrm{50 \%} \mathrm{(v/v)} \mathrm{ethanol} \mathrm{at} 70{ }^{\circ} \mathrm{C}$ for $4.5 \mathrm{~h}$. The mixtures were separated and $50 \%$ ethanol was used for washing the solid residues until the solvent in the thimble became colorless. The solid residues were washed thoroughly with water, freeze-dried and labeled as DP (dephenolization).

The process for removing sugar compounds is as follows: $100 \mathrm{~g}$ of EF or DP samples soaked in $300 \mathrm{~mL}$ distilled water and extracted at $85{ }^{\circ} \mathrm{C}$ for $4.5 \mathrm{~h}$. Then, the solid residues were recovered, thoroughly washed with water, and finally freezedried. EF samples subjected to the sugar removal process were labeled as RS (sugar removal). DP samples subjected to the sugar removal process were labeled as MP (multiple processes). EF samples subjected to no pretreatment were labeled as UN (untreated). Thus, there were four samples for subsequent treatment, namely, UN (untreated), DP (dephenolization), RS (sugar removal), and MP (multiple processes, a combination both dephenolization and sugar removal).

\subsection{Isolation of acetic acid lignin (AAL) fractions}

The experiments for isolating AAL fractions were conducted in a pressure glass reactor (volume: $500 \mathrm{~mL}$ ) with a magnetic stirrer. In a typical isolation experiment, the samples ( $20 \mathrm{~g})$ were poured into acetic acid/water $(400 \mathrm{~mL}, 9: 1, \mathrm{v} / \mathrm{v})$ and cooked at $120^{\circ} \mathrm{C}$ for $2 \mathrm{~h}$. Then, the extract was filtered and concentrated to about $5 \mathrm{~mL}$ under reduced pressure at $50{ }^{\circ} \mathrm{C}$. The concentrated solution was precipitated drop-wise in 10 volume of water. The crude lignin was separated by centrifugation, and subsequently dissolved in ethanol/1,2-dichloromethane solution $(1: 2, \mathrm{v} / \mathrm{v})$. The mixture was then centrifuged to remove insoluble substances. The supernatant was dropped in diethyl ether, then the precipitate was washed with petroleum ether and dried. The lignin fractions obtained from MP, DP, RS, and UN samples were defined as AAL-MP, AAL-DP, AAL-RS and AAL-UN, respectively.

\subsection{Characterization of AAL fractions}

The carbohydrate content of the lignin fractions was analyzed by high-performance anion-exchange chromatography (HPAEC). The samples were firstly hydrolyzed with $3 \% \mathrm{H}_{2} \mathrm{SO}_{4}$ at $105{ }^{\circ} \mathrm{C}$ for $2.5 \mathrm{~h}$. Then the monosaccharide content of the samples was analyzed according to the previous report. ${ }^{8}$

The molecular weights of acetylated lignin fractions were detected by gel permeation chromatography (GPC) according to the previous report. ${ }^{8}$

Analytical pyrolysis was performed with a CDS5000 pyrolyzer (CDS Analytical Inc., USA), interfaced to an Agilent 6890N/5975 gas chromatograph-mass selective detector (Agilent Technologies Inc., USA). In each experiment, $500 \mu \mathrm{g}$ lignin was placed in the pyrolysis unit and pyrolyzed at $500{ }^{\circ} \mathrm{C}$ for $20 \mathrm{~s}$. Pyrolysis products were separated on a capillary column (HP-5MS, $30 \mathrm{~m}$ $\times 0.25 \mathrm{~mm} \times 0.25 \mu \mathrm{m})$. Oven temperature was programmed from $50{ }^{\circ} \mathrm{C}(4 \mathrm{~min})$ to $100{ }^{\circ} \mathrm{C}$ at a rate of $20{ }^{\circ} \mathrm{C} \mathrm{min}{ }^{-1}$, and then ramped at $6{ }^{\circ} \mathrm{C} \min ^{-1}$ to $280{ }^{\circ} \mathrm{C}(5 \mathrm{~min})$.

Fourier transform infrared spectra (FT-IR) were recorded on a WQF-510 instrument (Beijing Rayleigh Analytical Instrument Corp., China). FT-IR analysis was conducted between $4000 \mathrm{~cm}^{-1}$ and $400 \mathrm{~cm}^{-1}$.

The thermal properties of lignin fractions were determined using a thermal analyzer (TGA-7, Perkin Elmer Cetus Instruments, USA) with a heating rate of $10{ }^{\circ} \mathrm{C} \mathrm{min}^{-1}$ under nitrogen atmosphere. The temperature ranged from $25{ }^{\circ} \mathrm{C}$ to $650{ }^{\circ} \mathrm{C}$.

2D HSQC NMR spectra were acquired with a Bruker Avance III HD $400 \mathrm{MHz}$ instrument (Bruker Co., Germany); $50 \mathrm{mg}$ of AAL fractions were dissolved in DMSO- $d 6(0.5 \mathrm{~mL})$. The F2 $\left({ }^{1} \mathrm{H}\right)$ and F1 
$\left({ }^{13} \mathrm{C}\right)$ spectral widths were 4000 and $20000 \mathrm{~Hz}$, respectively. ${ }^{31} \mathrm{P}$ NMR spectroscopy for the quantitative analysis was conducted according to the published procedure. ${ }^{15}$ Approximately $40 \mathrm{mg}$ of lignin fractions were dissolved in $500 \mu \mathrm{L}$ of anhydrous chloroform/pyridine ( $1: 1.6, \mathrm{v} / \mathrm{v}$, solvent A). Cyclohexanol (100 $\mu \mathrm{L}, 10.85 \mathrm{mg} \mathrm{mL}^{-1}$, in solvent A) and chromium(III) acetylacetonate $\left(100 \mu \mathrm{L}, 5.0 \mathrm{mg} \mathrm{mL}^{-1}\right.$, in solvent A) were added, respectively. Finally, $100 \mu \mathrm{L}$ of phosphorylating reagent (2-chloro-4,4,5,5tetramethyl-1,3,2-dioxaphospholane, TMDP) was added and kept at room temperature for $15 \mathrm{~min}$ before analysis.

\subsection{Antioxidant activities of acetic acid lignins}

The antioxidant activities of various AAL fractions were evaluated by 2,2-diphenyl-1-picryl-hydrazyl (DPPH) free radical assay according to a previous report. ${ }^{16}$ Different concentrations $(0.05$, $0.1,0.15,0.2,0.25,0.5,0.75$ and $1.0 \mathrm{mg} \mathrm{mL}^{-1}$ ) of lignin solution and $0.024 \mathrm{mg} \mathrm{mL}^{-1}$ DPPH solution were prepared in ethanol. Then, $150 \mu \mathrm{L}$ of AAL lignin solutions or ethanol were reacted with $2850 \mu \mathrm{L}$ of DPPH solution. After reaction at $25{ }^{\circ} \mathrm{C}$ for $20 \mathrm{~min}$, the $\mathrm{OD}_{517 \mathrm{~nm}}$ of the solution was monitored with a UV1100 spectrometer (Shanghai MAPADA Instruments Co., Ltd. China). The inhibition percentage (IP) of the DPPH free radical was measured by the following equation:

$$
\operatorname{IP}(\%)=\left(A_{0}-A_{1}\right) / A_{0} \times 100 \%
$$

where $A_{0}$ represents $\mathrm{OD}_{517 \mathrm{~nm}}$ of the blank sample, $A_{1}$ represents $\mathrm{OD}_{517 \mathrm{~nm}}$ of DPPH solution. The antioxidant activities of AAL fractions were characterized using the radical scavenging index (RSI), which was defined by the followed equation:

$$
\mathrm{RSI}=1 / \mathrm{EC}_{50}
$$

where $\mathrm{EC}_{50}$ is the effective concentration for achieving $50 \%$ IP.

\section{Results and discussion}

\subsection{Isolation and carbohydrate constitution of AAL fractions}

In this study, organosolv pretreatment and hot water pretreatment were performed at ambient pressure and at temperatures below $100{ }^{\circ} \mathrm{C}$ to remove phenolic compounds and sugar compounds. The yield of lignin extracted from materials after different pretreatments and the carbohydrate composition of AAL fractions are detailed in Table 1. The results show that the yields of AAL fractions extracted from pretreated materials were

\begin{tabular}{|c|c|c|c|c|c|c|c|c|}
\hline \multirow[b]{2}{*}{ Samples } & \multirow{2}{*}{$\begin{array}{l}\text { Yield } \\
(\%)\end{array}$} & \multirow{2}{*}{$\begin{array}{l}\text { Total sugar } \\
(\%)\end{array}$} & \multicolumn{6}{|c|}{ Carbohydrate content $^{a}(\%)$} \\
\hline & & & Ara & Gal & Glu & Xyl & Man & Uro \\
\hline AAL-MP & 47.0 & 2.7 & 11.7 & 3.8 & 5.3 & 74.4 & 0.2 & 4.7 \\
\hline AAL-DP & 52.2 & 1.3 & $\mathrm{ND}^{b}$ & 6.4 & 1.7 & 16.8 & 66.2 & ND \\
\hline AAL-RS & 49.5 & 0.1 & ND & 38.5 & ND & 61.4 & ND & ND \\
\hline AAL-UN & 61.7 & 0.5 & ND & 11.0 & 37.0 & 50.7 & 1.3 & ND \\
\hline
\end{tabular}

Table 1 Carbohydrates associated with AAL fractions

${ }^{a}$ Ara, arabinose; Gal, galactose; Glu, glucose; Xyl, xylose; Man, mannose; Uro, uronic acid. ${ }^{b} \mathrm{ND}$, not detected. lower than that from untreated samples. During the dephenolization pretreatment, polyphenols were removed along with low molecular weight lignins. ${ }^{17}$ Accordingly, the lignin yield from dephenolized materials (AAL-MP, 47.0\%; AAL-DP, 52.2\%) was less than that from untreated samples (AAL-UN, 61.7\%).

The sugar removal as a pretreatment process is necessary for the isolation of AAL. Since AAL was extracted with acetic acid, pseudo-lignin could be generated during the isolation. Pseudolignin can be formed by the combination of lignin and carbohydrate under acidic conditions. ${ }^{18}$ The dehydration reactions of some monosaccharides released after the hydrolysis of polysaccharides produces furfural and 5-hydroxymethylfurfural. ${ }^{19}$ Pseudo-lignin was formed by further polymerization and/or polycondensation reactions of furfural and 5-hydroxymethylfurfural. ${ }^{20}$ Using water-dimethyl sulfoxide (DMSO) mixtures as the reaction medium can effectively suppress the formation of pseudo-lignin because DMSO can inhibit 5hydroxymethylfurfural side reactions. ${ }^{21}$ In contrast, reducing the polysaccharide content in the sample would be more effective for the suppression of pseudo-lignin formation. The yield of AAL-RS was lower in comparison with AAL-UN. This confirmed that sugar removal of Chinese quince fruits in advance of AAL isolation is helpful to suppress the formation of pseudo-lignin.

As shown in Table 1, only a small amount of carbohydrates $(0.1-2.7 \%)$ remained in the AAL fractions, and they were mainly xylose and glucose with small amounts of arabinose, galactose, mannose and uronic acid. AAL-RS had lower carbohydrate content as compared with AAL-UN, indicating that a large amount of the hemicellulose was removed from the material during the treatment. ${ }^{22}$ However, AAL-MP had the highest carbohydrate content, with xylose and arabinose being the predominant sugars. This high carbohydrate content may be due to the presence of lignin-carbohydrate complexes. ${ }^{23}$ After the dephenolization pretreatment, pectin in cell walls was easier to dissolve and swell in the water compared to other types of pretreatment. This could inhibit the dissolution of hemicellulose in water, which may cause some lignin-carbohydrate complexes to remain in the lignin sample.

\subsection{FT-IR analysis}

Fig. 1 illustrates the fingerprint region of the FT-IR spectra of the AAL fractions. The bands are assigned according to the

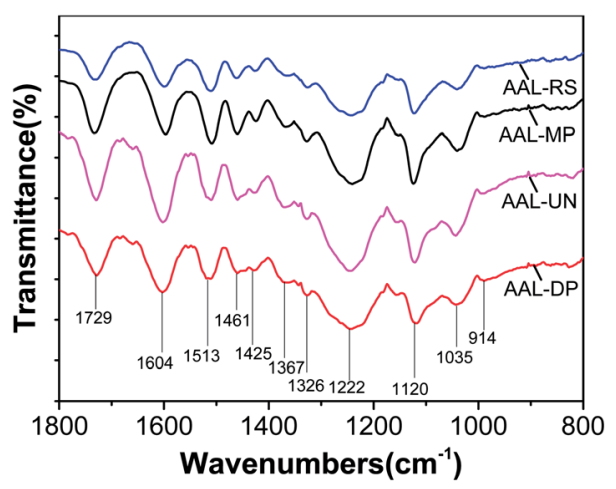

Fig. 1 FT-IR spectra of AAL fractions. 
previous report. ${ }^{24}$ The esterified phenolic acid and acetyl groups associated with xylose or uronic acid residues of hemicelluloses give one band at $1729 \mathrm{~cm}^{-1} .{ }^{25}$ The aromatic skeletal vibrations give absorptions at 1604, 1513 and $1425 \mathrm{~cm}^{-1}$. The band at $1367 \mathrm{~cm}^{-1}$ corresponds to aliphatic $\mathrm{C}-\mathrm{H}$ in $\mathrm{CH}_{3}$. The band at $1326 \mathrm{~cm}^{-1}$ is assigned to sinapyl (S) units. The band at $1222 \mathrm{~cm}^{-1}$ is assigned to $\mathrm{S}$ and $p$-coumaryl units. Bands at $1120 \mathrm{~cm}^{-1}$ and $1035 \mathrm{~cm}^{-1}$ originate from aromatic $\mathrm{C}-\mathrm{H}$ bonds in $\mathrm{S}$ and guaiacyl (G) units, respectively. The band at $825 \mathrm{~cm}^{-1}$ is related to $\mathrm{C}-\mathrm{H}$ out-of-plane bending of $\mathrm{S}$ units and $p$-hydroxyphenyl $(\mathrm{H})$ units. $\mathrm{C}-\mathrm{H}$ out-of-plane bending of $\mathrm{G}$ units is observed at $914 \mathrm{~cm}^{-1}$.

The spectra of AAL fractions in the $1800-800 \mathrm{~cm}^{-1}$ region were similar. However, slight variations in some peaks could also be observed. The spectra of AAL-UN and AAL-DP exhibited weaker peaks at $1425 \mathrm{~cm}^{-1}$ and $1461 \mathrm{~cm}^{-1}$ compared to AAL-RS and AAL-MP, which are assigned to $\mathrm{CH}_{2}$ and $\mathrm{C}-\mathrm{H}$ deformation vibrations in lignin, respectively. This may be related to a greater number of $\mathrm{CH}_{2}$ groups in the side chains of the $\mathrm{G}$ and $S$ units of AAL-MP and AAL-RS than in comparable units of AALDP and AAL-UN (see data in Table 2).

\subsection{Thermal analysis}

TG and DTG curves of the various AAL fractions are shown in Fig. 2. In the temperature range of $25^{\circ} \mathrm{C}$ to $200{ }^{\circ} \mathrm{C}$, the reactions were all endothermic, mainly attributed to the removal of moisture from samples. From $200-650{ }^{\circ} \mathrm{C}$, the degradation was accompanied by some reactions. ${ }^{26}$ AAL-DP showed the highest thermo-decomposition rate as compared to AAL-RS and AALUN. However, AAL-MP had a large amount of carbohydrate and low thermo-decomposition rate, which may be associated with the structural differences in the four AAL fractions. Because of the different pretreatment methods, lignin in different cell walls with different structural features could be obtained. The ether linkages such as the $\beta-O-4$ structure were cleaved between $200{ }^{\circ} \mathrm{C}$ and $350{ }^{\circ} \mathrm{C}$. The oxidation of lignin side chains happened at around $400{ }^{\circ} \mathrm{C}$. Above $400{ }^{\circ} \mathrm{C}$, the gas products $\left(\mathrm{CH}_{4}, \mathrm{H}_{2}\right.$, $\mathrm{CO}$ etc. $)$ evolved from lignin pyrolysis. ${ }^{27}$ The $\mathrm{H}_{2}$ originated from the cracking and deformation of $\mathrm{C}=\mathrm{C}$ and $\mathrm{C}-\mathrm{H}$, while the $\mathrm{CH}_{4}$ was released from the cracking of the methoxy groups.

Temperatures for the highest velocity of degradation revealed the thermal stability of different lignin samples. As shown in Fig. 2B, the temperatures corresponding to the maximal rate of decomposition (DTG ${ }_{\max }$ ) of the AAL fractions were observed to be $423{ }^{\circ} \mathrm{C}, 332{ }^{\circ} \mathrm{C}, 329^{\circ} \mathrm{C}$ and $300{ }^{\circ} \mathrm{C}$ for AALMP, AAL-DP, AAL-RS and AAL-UN, respectively. The first peak of the DTG curve for AAL-MP was located at $329{ }^{\circ} \mathrm{C}$, this peak represented the decomposition of carbohydrates in LCC. The second peak, which was located at $423{ }^{\circ} \mathrm{C}$, mainly represented the decomposition of lignin in LCC. It could be inferred that the decomposition of carbohydrates and lignin in LCC happened in succession. AAL-MP was more stable than the other samples, and this was supported by the fact that AAL-MP had the highest molecular weight. The maximum decomposition temperature of AAL was increased after the sugars and phenolic compounds

Table 2 Relative abundances (\%) of the lignin-derived products from Py-GC/MS of AAL fractions

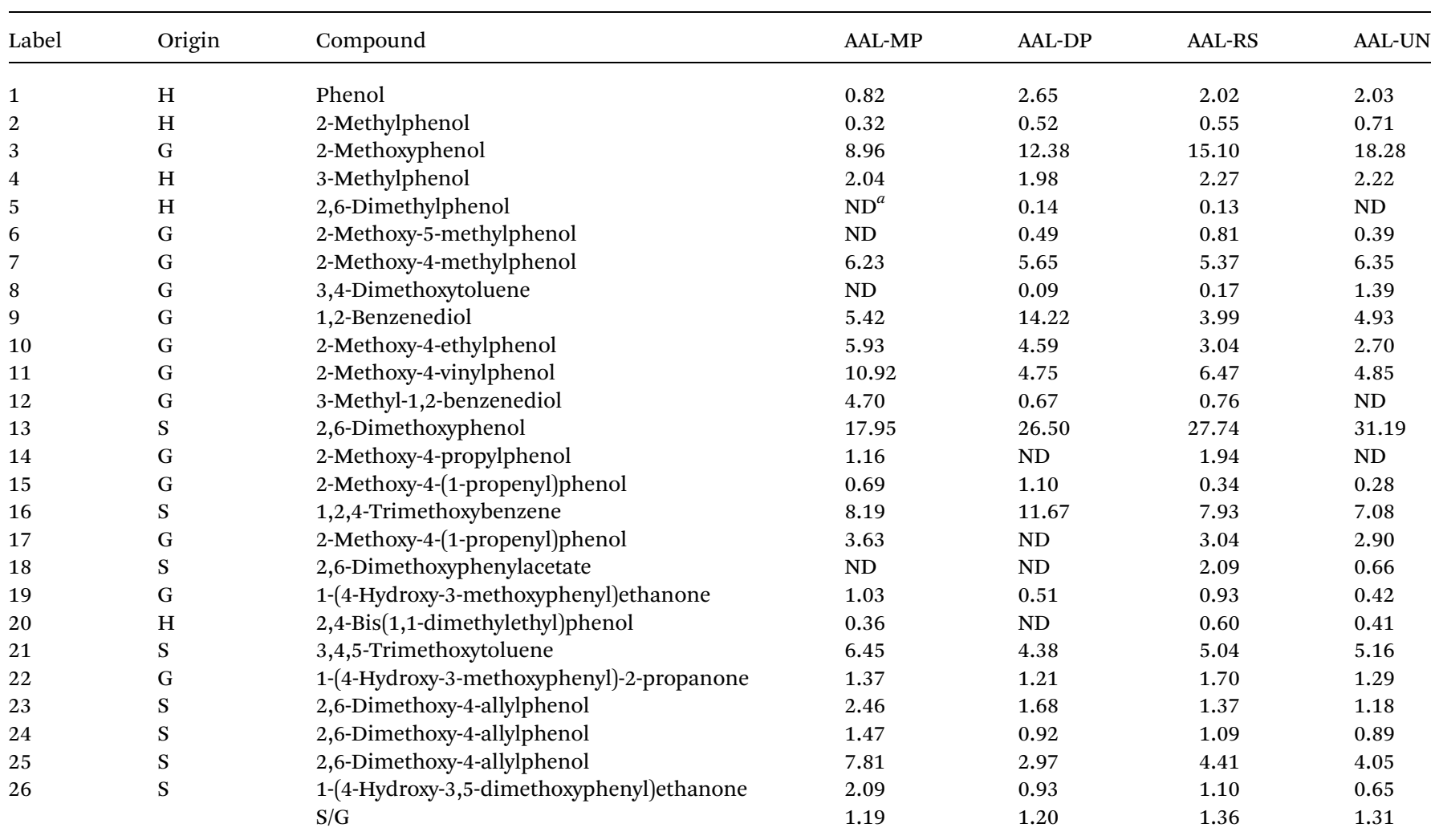

${ }^{a} \mathrm{ND}$, not detected. 

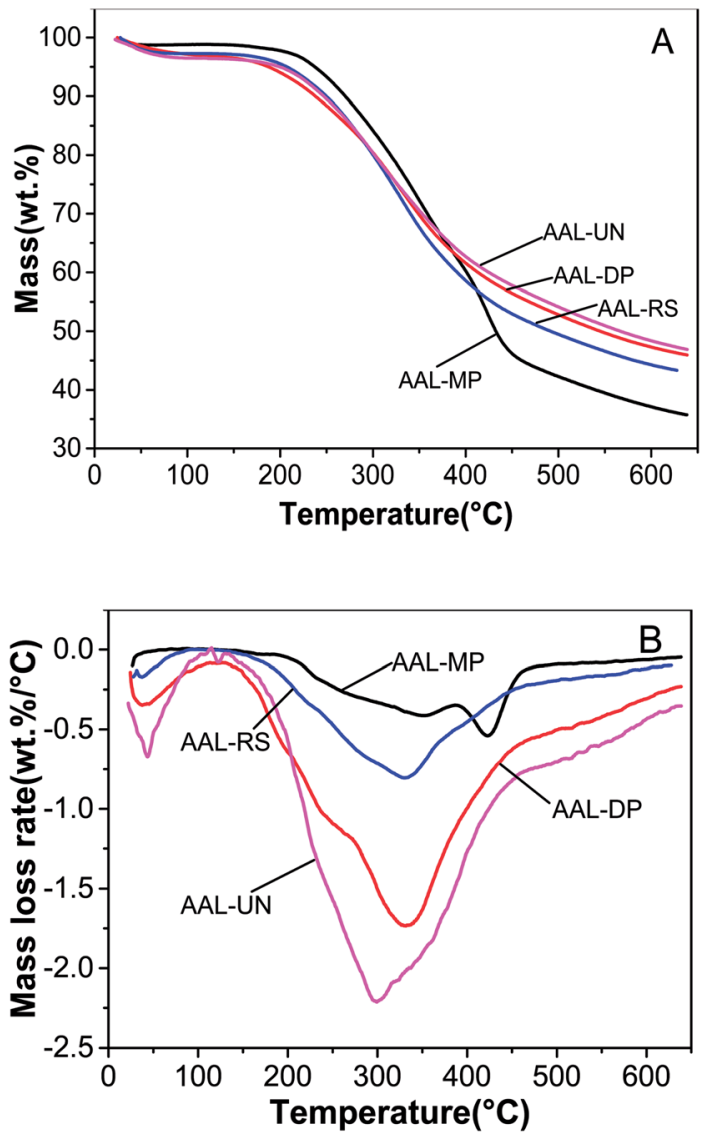

Fig. 2 Thermogravimetric (TG) and derivative thermogravimetric (DTG) curves of AAL fractions. (A) TG; (B) DTG.

had been removed, suggesting that more stable lignin structures were formed after the pretreatment. ${ }^{26}$ It was found that the levels of solid residue at $650{ }^{\circ} \mathrm{C}$ were $35.7 \%$ for AAL-MP, $46.0 \%$ for AAL-DP, $43.3 \%$ for AAL-RS and $46.9 \%$ for AAL-UN. The results indicated that more condensed lignin structures were generated in AAL-RS and AAL-DP.

\subsection{Py-GC/MS analysis}

Pyrolysis-gas chromatography/mass spectrometry (Py-GC/MS) is a reliable method for the characterization of lignin; it requires little lignin sample and a short time for analysis. ${ }^{28}$ The total ion chromatograms of different samples obtained by Py-GC/MS are shown in Fig. S1; $\uparrow$ the identified compounds and corresponding structures are shown in Table 2 and Fig. S2, $\dagger$ respectively. As shown in Table 2, thirty lignin-derived compounds were identified, including six $p$-hydroxyphenyl-type compounds; sixteen guaiacyltype compounds; eight syringyl-type compounds. Both G and S units with various side chains were detected, confirming the presence of lignin. Syringyl lignin-derived compounds were the most abundant aromatic pyrolysis degradation products in all samples. The major pyrolytic products in untreated and pretreated samples were derived from $\mathrm{S}$ units, including 2,6-dimethoxyphenol; 1,2,4-trimethoxybenzene; 3,4,5-trimethoxytoluene; 2,6dimethoxy-4-allylphenol. G-type phenols could be released by the direct breaking of the $\beta-O-4$ bond. 1,2-Benzenediol, 2- methoxyphenol together with some methyl, ethyl and vinyl analogues were typical degradation products of guaiacyl lignin in all samples. The relative proportions of $\mathrm{H}, \mathrm{S}$ and $\mathrm{G}$ lignins differed in the various AAL fractions. It was obvious that 2,6-dimethoxyphenol (13) content was reduced after the dephenolizing pretreatment. An obvious decrease in 2-methoxyphenol (3) content was found both in all the dephenolized samples and the samples after sugar removal. Increases in the content of 1,2-benzenediol (9) in AAL-DP and 2-methoxy-4-vinylphenol (11) in AAL-MP were also found. All these differences in the content of lignin-derived compounds indicated that the structural features of AAL fractions were varied.

High levels of 2-methoxy-4-vinylphenol were detected in the pyrolysis products of AAL samples. This may have arisen mostly from ferulate via decarboxylation during pyrolysis and partially from lignin; $;^{29}$ therefore, the $\mathrm{S} / \mathrm{G}$ should be estimated by ignoring the peak area of 2-methoxy-4-vinylphenol. A decrease in the $\mathrm{S} / \mathrm{G}$ ratio was observed in pretreatment samples (AAL-MP and AAL-DP). The results revealed the decrease in syringyl-type lignin content in dephenolized samples and indicated that there was an association between syringyl-type lignin and polyphenol in Chinese quince pulp. ${ }^{30}$

\subsection{GPC analysis}

The molecular weight distributions of AAL fractions are shown in Table 3 and Fig. S3. $\dagger$ As shown in Fig. S3, $\uparrow$ the maximum peaks of AAL-MP and AAL-DP obviously shifted to the higher molecular weight region in contrast to the peaks of AAL-UN which did not shift. Part of the "low molecular" fractions may have been lost during dephenolization, since Brauns' lignin dissolved in solution when the material was extracted with neutral alcoholic solvents. ${ }^{31}$ As shown in Table $3, M_{\mathrm{w}}$ and $M_{\mathrm{n}}$ of AAL-MP and AAL-DP were higher than those of AAL-UN. This result could be attributed to the solubility of low-molecular-weight lignin fractions in the $75 \%$ ethanol during dephenolization. In addition, the high polydispersities of AAL-MP and AAL-DP were consistent with the broad peaks in the chromatogram. After sugar removal, AAL-RS exhibited a lower molecular weight than AAL-UN. This may be due to the reduction of linked carbohydrate chains in lignin, since lignincarbohydrate linkage may increase the molar mass of the lignin by increasing the hydrodynamic volume of lignin. ${ }^{32}$ It was noteworthy that small shoulders were visible in the low molecular region (at $M_{\mathrm{w}}$ 500-700, 600-800 and 1000-1500) of the distribution curve of AAL fractions. This may be related to the degradation of lignin during acidolysis and the formation of low molecular weight material. ${ }^{33}$

Table 3 Weight-average $\left(M_{w}\right)$ and number-average $\left(M_{n}\right)$ molecular weights of AAL fractions

\begin{tabular}{lrlll}
\hline & $M_{\mathrm{w}}$ & $M_{\mathrm{n}}$ & $M_{\mathrm{w}} / M_{\mathrm{n}}$ & $M_{\mathrm{p}}{ }^{a}$ \\
\hline AAL-MP & 9340 & 5860 & 1.6 & 8690 \\
AAL-DP & 6630 & 4070 & 1.6 & 4990 \\
AAL-RS & 5070 & 3420 & 1.5 & 4040 \\
AAL-UN & 5670 & 4020 & 1.4 & 4500 \\
${ }^{a}$ Peak molecular weight. & & &
\end{tabular}


Table 4 Quantification of the AAL factions by ${ }^{31}$ P NMR

\begin{tabular}{lllll}
\hline & \multicolumn{2}{l}{ Content $\left(\mathrm{mmol} \mathrm{g}^{-1}\right)$} & \\
\cline { 2 - 5 } Functional groups & AAL-MP & AAL-DP & AAL-RS & AAL-UN \\
\hline Aliphatic hydroxyl OH & 0.92 & 1.47 & 1.33 & 1.34 \\
Syringyl phenolic OH & 0.57 & 0.56 & 0.64 & 0.48 \\
Guaiacyl phenolic OH & 1.36 & 1.42 & 1.57 & 1.61 \\
$p$-Hydroxyphenyl phenolic & 0.05 & 0.11 & 0.08 & 0.08 \\
OH & & & & \\
Carboxylic OH (COOH) & 0.08 & 0.16 & 0.17 & 0.35 \\
Total phenolic OH & 1.98 & 2.09 & 2.30 & 2.18 \\
Total OH & 2.98 & 3.72 & 3.80 & 3.87 \\
& & & &
\end{tabular}

\subsection{Quantitative ${ }^{31} \mathrm{P}$ NMR analysis}

Quantitative ${ }^{31} \mathrm{P}$ NMR spectra were obtained to explore the structural transformations of AAL fractions during the pretreatments, and the results are presented in Table 4 . The ${ }^{31} \mathrm{P}$ NMR signals resonating between 135.5 and $134.2 \mathrm{ppm}$, were assigned to carboxyl groups. The signals of aliphatic hydroxyl $\mathrm{OH}$ were detected between 148.8 and $145.9 \mathrm{ppm}$, which were mainly derived from hydroxylated lignin lateral chains. The signals between 143.0 and $141.4 \mathrm{ppm}$ were attributed to the syringyl phenolic $\mathrm{OH}$, while those between 138.8 and $140.2 \mathrm{ppm}$ were assigned to the guaiacyl phenolic $\mathrm{OH}$. The peaks in the 138.5 and 136.0 ppm range were attributed to $p$-hydroxy-phenyl $\mathrm{OH}$. The total phenolic $\mathrm{OH}$ content in AAL-RS was higher than other AAL fractions. This suggested that more $\mathrm{S}$ and G-type phenolic $\mathrm{OH}$ were dissociated during the process of sugar removal due to the cleavage of $\beta-O-4$ linkages. ${ }^{34}$ Since the phenolic $\mathrm{OH}$ played an important role in the antioxidant activities, AAL-RS was superior to other samples in antioxidant activities as revealed by the DPPH radical scavenging activities (see Fig. 5).

\subsection{D HSQC NMR analysis}

The structural characteristics of AAL-RS and AAL-UN were described using the 2D HSQC NMR technique. The signals were assigned according to the previous publications. ${ }^{15,35}$ The HSQC spectra of AAL-RS and AAL-UN are shown in Fig. 3, the main substructures presented in AAL-RS and AAL-UN are shown in Fig. 4, and the specific chemical shifts of the substructures were listed in Table S1. $\dagger$ Two main regions were depicted corresponding to side-chain $\left(\delta_{\mathrm{C}} / \delta_{\mathrm{H}} 50-90 / 2.5-6.0\right)$ and aromatic $\left(\delta_{\mathrm{C}} /\right.$ $\delta_{\mathrm{H}}$ 90-140/5.5-8.0) ${ }^{13} \mathrm{C}-{ }^{1} \mathrm{H}$ correlations. Except for the mentioned regions, an aliphatic region (10-45/0.5-3 ppm, not shown in figures) was observed, which revealed the presence of branched and unsaturated fatty chains. ${ }^{36}$

Signals from methoxyl groups $\left(\mathrm{OCH}_{3}, \delta_{\mathrm{C}} / \delta_{\mathrm{H}} 56.4 / 3.68 \mathrm{ppm}\right)$ and $\beta-O-4$ ether units $\left(\delta_{\mathrm{C}} / \delta_{\mathrm{H}} 60.1 / 3.29 \mathrm{ppm}\right.$, substructure $\left.\mathrm{A}\right)$ were the prominent signals. Specifically, signals from $\beta-O-4$ structures were observed with their $\mathrm{C}-\mathrm{H}$ correlations for $\alpha, \gamma$ positions at $\delta_{\mathrm{C}} / \delta_{\mathrm{H}} 72.5 / 4.85 \mathrm{ppm}, \delta_{\mathrm{C}} / \delta_{\mathrm{H}} 60.1 / 3.29 \mathrm{ppm}$, respectively. Moreover, the $\mathrm{C}_{\beta}-\mathrm{H}_{\beta}$ correlations in $\beta-O-4$ structures linked to $\mathrm{G}$ units were also observed at $\delta_{\mathrm{C}} / \delta_{\mathrm{H}} 83.9 / 4.32 \mathrm{ppm}$. Signals at $\delta_{\mathrm{C}} / \delta_{\mathrm{H}}$ 86.1/4.64 ppm, $\delta_{\mathrm{C}} / \delta_{\mathrm{H}} 54.3 / 3.01 \mathrm{ppm}$, and $\delta_{\mathrm{C}} / \delta_{\mathrm{H}} 71.9 / 3.80-$ 4.18 ppm correlated with $\mathrm{C}_{\alpha}-\mathrm{H}_{\alpha}, \mathrm{C}_{\beta}-\mathrm{H}_{\beta}$, and $\mathrm{C}_{\gamma}-\mathrm{H}_{\gamma}$ of $\beta-\beta$ (resinol) substructures, respectively. Besides these linkages, $\mathrm{C}_{\gamma}-\mathrm{H}_{\gamma}$ correlations $\left(\delta_{\mathrm{C}} / \delta_{\mathrm{H}} 63.9 / 3.99 \mathrm{ppm}\right)$ in the phenylcoumaran
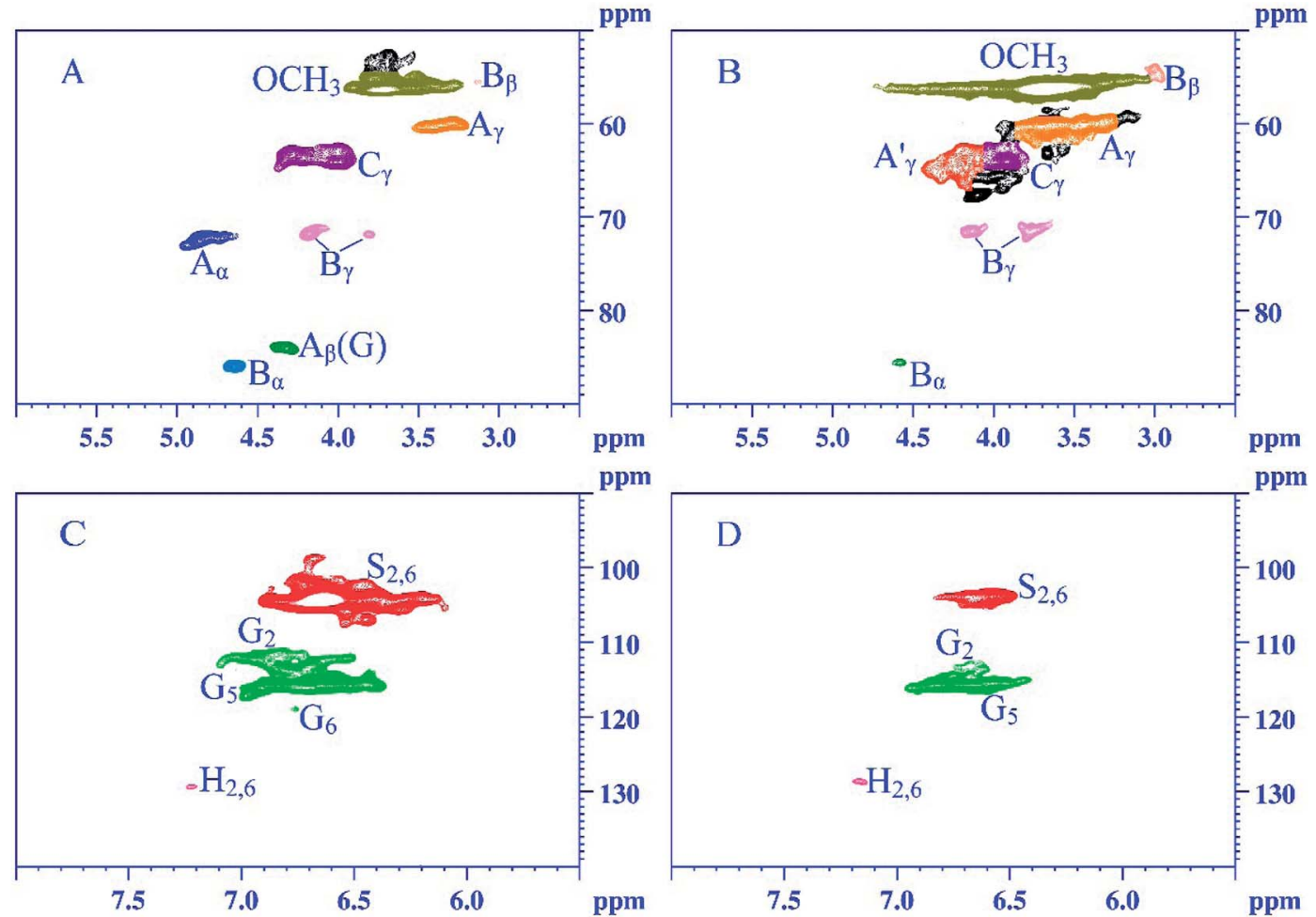

Fig. 3 2D HSQC spectra of AAL-UN and AAL-RS obtained from Chinese quince fruit. The side-chain region: (A) AAL-UN; (B) AAL-RS. The aromatic region: (C) AAL-UN; (D) AAL-RS. 


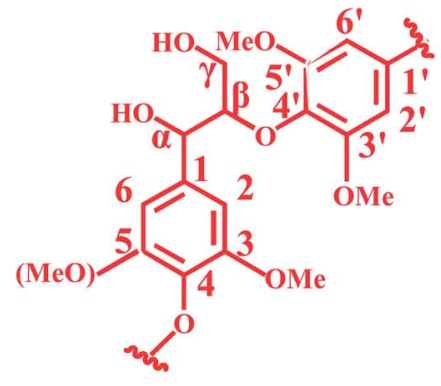

A

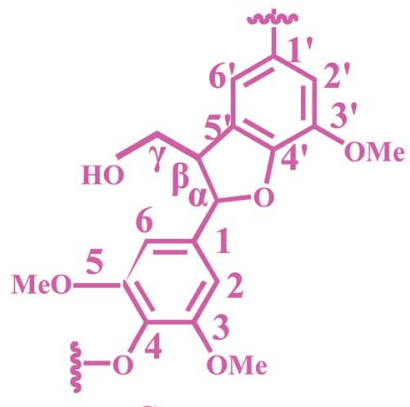

C

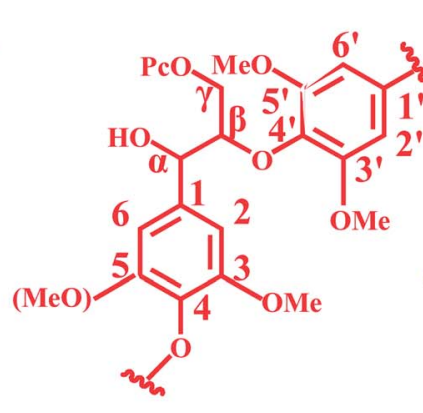

$\mathrm{A}^{\prime}$

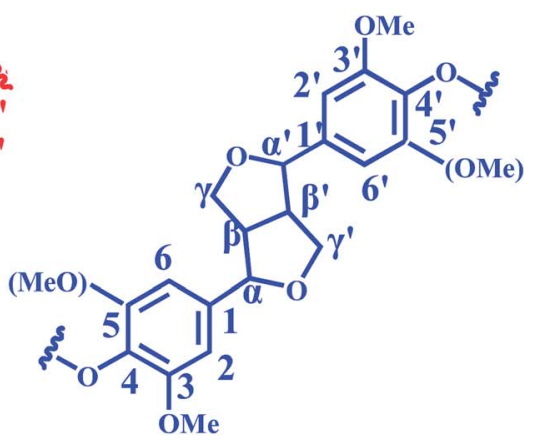

B

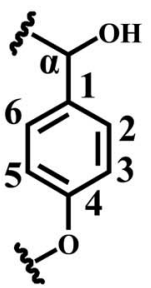

$\mathrm{H}$
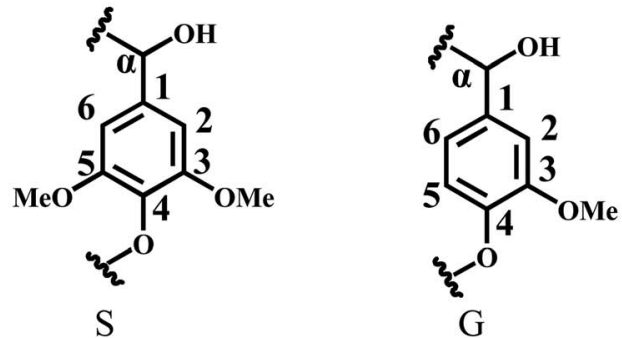

Fig. 4 Main substructures presented in AAL-UN and AAL-RS: (A) $\beta-O-4$ aryl ether substructures; ( $\left.A^{\prime}\right) \gamma$-acylated $\beta-O-4$ aryl ether substructures; (B) resinol substructures; (C) phenylcoumaran substructures; $(H)$ p-hydroxyphenyl units; $(S)$ syringyl units; (G) guaiacyl units.

substructure were also found in the spectra. It was worth noting that the $\mathrm{C}_{\gamma}-\mathrm{H}_{\gamma}$ correlation in the $\gamma$-acylated $\beta$-O-4 substructure $\left(\mathrm{A}^{\prime}\right)$ was observed at $\delta_{\mathrm{C}} / \delta_{\mathrm{H}} 63.8 / 4.28 \mathrm{ppm}$ in the spectrum of AAL-RS.

The composition of lignin was revealed by the aromatic region of the HSQC spectra. In the aromatic region, the signals from $\mathrm{G}, \mathrm{S}$ and $\mathrm{H}$ units can be clearly observed in the HSQC spectra, suggesting that lignin from Chinese quince fruit is G-S-H type. The $\mathrm{S}$ units showed a remarkable signal for the $\mathrm{C}_{2,6}-\mathrm{H}_{2,6}\left(\mathrm{~S}_{2,6}\right)$ at $\delta_{\mathrm{C}} / \delta_{\mathrm{H}} 104.5 / 6.64 \mathrm{ppm}$. The $\mathrm{C}-\mathrm{H}$ correlations from $G$ units for the $G_{2}, G_{5}$ and $G_{6}$ positions were at 112.4/ $6.93 \mathrm{ppm}, 115.9 / 6.70 \mathrm{ppm}$, and $119.4 / 6.74 \mathrm{ppm}$, respectively. $\mathrm{G}_{2}$ was the condensed lignin structure. The $p$-hydroxyphenyl units were recognized by the correlation for $\mathrm{C}_{2,6}-\mathrm{H}_{2,6}$ at $\delta_{\mathrm{C}} / \delta_{\mathrm{H}} 129.4 /$ $7.21 \mathrm{ppm}$.

Quantitative analysis of the lignin structures is important for investigating lignin. The semi-quantitative method based on 2D-HSQC spectra was commonly used in the quantitative analysis of lignin. The relative abundance of lignin structures was calculated basing on the peak area normalization method. ${ }^{37}$ As listed in Table 5 , the relative content of the $\beta-O-4$ substructure $(45.95 \%)$ was most abundant in AAL-UN, followed by $\beta$ $\beta(30.27 \%)$ and $\beta-5$ (23.77\%) substructures. As compared with AAL-UN, AAL-RS demonstrated a lower relative proportion of $\beta$ $\beta$ substructure and a higher relative proportion of $\beta-5$ substructure. No obvious differences in the content of $\beta-O-4$ substructures were found between AAL-UN and AAL-RS, revealing that less serious degradation occurred during the pretreatments. The S/G ratios of the AAL-UN and AAL-RS, based on NMR data, were 1.90 and 1.66, respectively; these ratios were higher than the results obtained from the Py/GC-MS. This may be associated with the demethoxylation of syringyl (S)-type compounds during pyrolysis; demethoxylation could have led to the formation of monomethoxyphenols (i.e. guaiacyl units) and thus, could have effectively decreased the S/G ratio. ${ }^{38}$

\subsection{Assessment of antioxidant activity}

The antioxidant activities of various AAL fractions were evaluated as the capacity to scavenge DPPH free radicals, and the results are shown in Fig. 5. All the lignin fractions exhibited antioxidant capability, and their DPPH inhibitory effect increased with increasing solution concentration.

Some studies have reported that low molecular weight lignin has high antioxidant activity, which is attributed to the extensive formation of new aromatic hydroxyl groups during lignin depolymerization. Carbohydrates linked adjacent to the lignin can generate hydrogen bonding with lignin phenolic groups, which may diminish the antioxidant capacity of the lignins. ${ }^{39}$ The radical-scavenging index (RSI) values of AAL-MP, AAL-DP,

Table 5 Quantification of substructures from AAL fractions by 2DHSQC NMR

Percentage (\%)

\begin{tabular}{|c|c|c|}
\hline Lignin inter-unit linkages & AAL-UN & AAL-RS \\
\hline$\beta-O-4$ Aryl ethers (A) & 45.95 & 45.50 \\
\hline$\beta-\beta$ (Resinols) (B) & 23.77 & 15.75 \\
\hline$\beta-5$ (Phenylcoumarans) (C) & 30.27 & 38.76 \\
\hline $\mathrm{S} / \mathrm{G}^{\text {ratio }^{a}}$ & 1.90 & 1.66 \\
\hline
\end{tabular}

${ }^{a} \mathrm{~S} / \mathrm{G}$ ratio was obtained by the equation: $\mathrm{S} / \mathrm{G}$ ratio $=0.5 \mathrm{IS}_{2,6} / \mathrm{IG}_{2}$. 
AAL-RS and AAL-UN were 3.45, 4.55, 5.56 and 5.00, respectively. Obviously, AAL-RS had significantly higher antioxidant activity than AAL-MP, AAL-DP, and AAL-UN. This may be due to the lower molecular weight and carbohydrate content of AAL-RS as compared with other samples. ${ }^{40}$ It was worth noting that the RSI value of AAL fractions from Chinese quince fruits was higher than that of lignin fractions in the previous report. ${ }^{\mathbf{4 1}}$ These results indicated the good antioxidant activity of the AAL fractions from Chinese quince fruits.

Some reports have revealed the lignin structure-antioxidant activity relationship. ${ }^{39,42}$ Non-etherified phenolic hydroxyl groups, ortho-methoxy groups and $\mathrm{CH}_{2}$ groups in the $\alpha$-position in the side chains had a positive effect on antioxidant activity, while the $\alpha$-carbonyl groups in the aliphatic chain drastically decreased the radical scavenging activity of lignin. The influence of a carbon double bond conjugated with an aromatic ring on antioxidant activity was negative, while the influence of a double bond between the outermost carbon atoms was positive. In this sense, AAL-MP presented more lignin-derived compounds with a double bond or a carbonyl group in the side-chain of phenylpropane units (structures 11, 15, 17 or 19, 26 in Fig. S2 $\dagger$ ), in comparison with other samples. AAL-RS had a higher RSI value as compared with AAL-DP (4.55 and 5.56, respectively). This can be attributed to the fact that AAL-RS has relatively more phenolic structures with ortho-methoxy groups (structures 3, 6, 7, 13, 14, 16 exhibited in Fig. S2 $\dagger$ ), more $\mathrm{CH}_{2}$ groups (structures 7, 10, 14, 22, 23, 24, 25 exhibited in Fig. S2 $\dagger$ ) and a double bond between $\mathrm{C}_{\beta}$ and $\mathrm{C}_{\gamma}$ (structures 23, 24, 25 exhibited in Fig. S2 $\dagger$ ).

Some studies have demonstrated that lignins do not irritate the eyes or skin when used as topical formulations for eye and
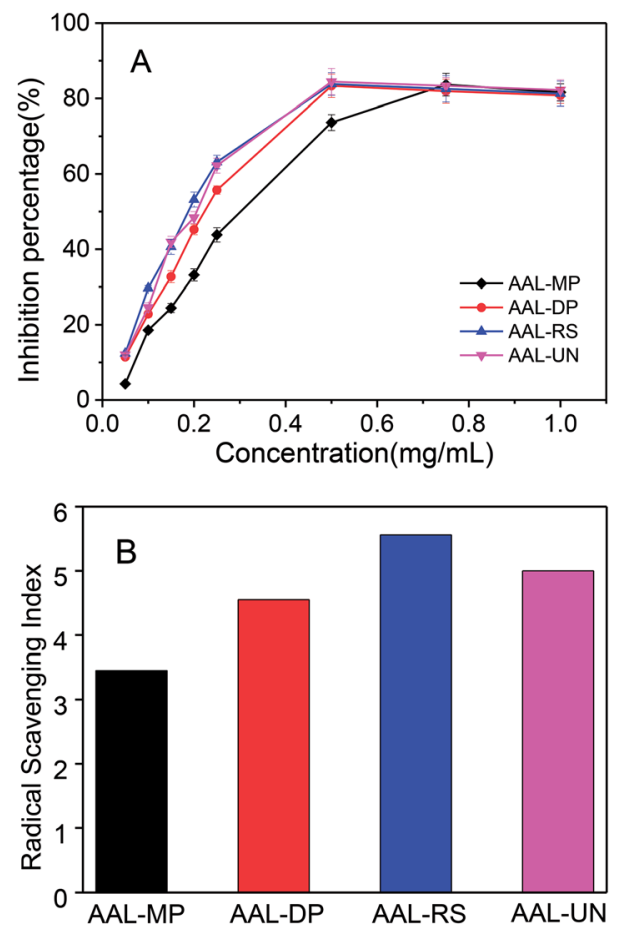

Fig. 5 Antioxidant activities against DPPH (A) and RSI value (B) of the AAL fractions. skin irrigation. ${ }^{43}$ Some reports suggest that the lignin in dietary fiber can inhibit the growth of cancer cells by suppressing the activity of enzymes related to the generation of superoxide anion radicals. ${ }^{44}$ The relatively strong antioxidant properties of lignin from Chinese quince fruit, as shown in the present study, suggests that it has potential applications in the nutraceutical and cosmetic industries.

\section{Conclusions}

Different pretreatment processes (dephenolization, sugar removal, multiple processes) were applied to Chinese quince fruit pulp before lignin extraction by acetic acid. The influence of different pretreatments on the structural features and antioxidant activities of the extracted lignin fractions was evaluated. All pretreatments reduced the yield of lignin. In addition, after sugar removal, both the carbohydrate content and molecular weight of the extracted lignins decreased, while dephenolization and multiple processing resulted in a higher carbohydrate content and molecular weight, as compared to the untreated sample. After pretreatments, all lignin fractions had a higher DTG $_{\text {max }}$ than the untreated sample. Sugar removal enhanced the antioxidant activity of lignin fractions but resulted in a slight decrease in the $\mathrm{S} / \mathrm{G}$ ratio. Removing sugar was necessary for yielding lignins of high purity and functionality from the fruit of Chinese quince. Dephenolization or multiple processes (a combination of both dephenolization and sugar removal) before lignin extraction were helpful for obtaining high molecular lignin fractions. The study provides a reference for biomass refining.

\section{Conflicts of interest}

There are no conflicts to declare.

\section{Acknowledgements}

This project was supported by the Program for Henan Scientific and Technological Innovation Talents of Colleges and Universities (19HASTIT012). We are grateful to the anonymous reviewers for their constructive comments on revision of the manuscript.

\section{References}

1 Y. Hamauzu, T. Inno, C. Kume, M. Irie and K. Hiramatsu, J. Agric. Food Chem., 2006, 54, 765-772.

2 Y. Hamauzu, M. Irie, M. Kondo and T. Fujita, Food Chem., 2008, 108, 488-495.

3 R. Sawai-kuroda, S. Kikuchi, Y. K. Shimizu, Y. Sasaki, K. Kuroda, T. Tanaka, T. Yamamoto, K. Sakurai and K. Shimizu, J. Ethnopharmacol., 2013, 146, 866-872.

4 J. S. Kim, Y. Y. Lee and T. H. Kim, Bioresour. Technol., 2016, 199, 42-48.

5 Y. Ikeda, T. Phakkeeree, P. Junkong, H. Yokohama, P. Phinyocheep, R. Kitano and A. Kato, RSC Adv., 2017, 7, 5222-5231. 
6 N. Balasundram, K. Sundram and S. Samman, Food Chem., 2006, 99, 191-203.

7 W. Gong, Z. Xiang, F. Ye and G. Zhao, Ind. Crops Prod., 2016, 91, 340-349.

8 M. F. Li, P. Yu, S. X. Li, X. F. Wu, X. Xiao and J. Bian, Energy Convers. Manage., 2017, 148, 1426-1437.

9 Y. Hamauzu, H. Yasui, T. Inno, C. Kume and M. Omanyuda, J. Agric. Food Chem., 2005, 53, 928-934.

10 Y. Kim, E. Ximenes, N. S. Mosier and M. R. Ladisch, Enzyme Microb. Technol., 2011, 48, 408-415.

$11 \mathrm{~S} . \quad$ N. R. Thammasittirong, P. Chatwachirawong, T. Chamduang and A. Thammasittirong, Ind. Crops Prod., 2017, 108, 598-603.

12 W. Lange and O. Faix, Holzforschung, 2005, 53, 519-524.

13 C. Gong and B. Bujanovic, J. Bioresour. Bioprod., 2016, 1, 2229.

14 R. Sawai, K. Kuroda, T. Shibata, R. Gomyou, K. Osawa and K. Shimizu, J. Ethnopharmacol., 2008, 118, 108-112.

15 J. L. Wen, S. L. Sun, B. L. Xue and R. C. Sun, Holzforschung, 2013, 67, 613-627.

16 Z. Qin, X. D. Wang, H. M. Liu, D. M. Wang and G. Y. Qin, Bioresour. Technol., 2018, 262, 212-220.

17 G. Hu, C. Cateto, Y. Pu, R. Samuel and A. J. Ragauskas, Energy Fuels, 2012, 26, 740-745.

18 P. Sannigrahi, H. K. Dong, S. Jung and A. Ragauskas, Energy Environ. Sci., 2011, 4, 1306-1310.

19 F. Hu, S. Jung and A. Ragauskas, ACS Sustainable Chem. Eng., 2013, 1, 62-65.

20 F. Hu, S. Jung and A. Ragauskas, Bioresour. Technol., 2012, 117, 7-12.

21 F. Hu and A. Ragauskas, RSC Adv., 2013, 4, 4317-4323.

22 M. Wu, D. H. Zhao, J. H. Pang, X. M. Zhang, M. F. Li, F. Xu and R. C. Sun, Ind. Crops Prod., 2015, 66, 123-130.

23 J. C. del Río, P. Prinsen, E. M. Cadena, A. T. Martínez, A. Gutiérrez and J. Rencoret, Planta, 2016, 243, 1143-1158.

24 O. Faix, Holzforschung, 1991, 45(suppl.), 21-27.

25 X. Xiao, J. Bian, M. F. Li, H. Xu, B. Xiao and R. C. Sun, Bioresour. Technol., 2014, 159, 41-47.

26 J. L. Wen, B. L. Xue, S. L. Sun and R. C. Sun, J. Chem. Technol. Biotechnol., 2013, 88, 1663-1671.
27 H. Kawamoto, J. Wood Sci., 2017, 63, 117-132.

28 T. Ohra-Aho, F. J. B. Gomes, J. L. Colodette and T. Tamminen, J. Anal. Appl. Pyrolysis, 2015, 101, 166-171.

29 J. C. del Río, P. Prinsen, J. Rencoret, L. Nieto, J. JiménezBarbero, J. Ralph, A. T. Martínez and A. Gutierrez, J. Agric. Food Chem., 2012, 60, 3619-3634.

30 S. A. L. Morais, E. A. Nascimento, C. R. A. A. Queiroz, D. PilóVeloso and M. G. Drumond, J. Braz. Chem. Soc., 1999, 10, 447-452.

31 E. Hiltunen, L. Alvila and T. T. Pakkanen, Wood Sci. Technol., 2006, 40, 575-584.

32 A. S. Jaaskelainen, Y. Sun, D. S. Argyropoulos, T. Tamminen and B. Hortling, Wood Sci. Technol., 2003, 37, 91-102.

33 C. Alvarez-Vasco, R. Ma, M. Quintero, M. Guo, S. Geleynse, K. K. Ramasamy, M. Wolcottc and X. Zhang, Green Chem., 2016, 18, 5133-5141.

34 B. Wang, X. J. Shen, J. L. Wen, L. Xiao and R. C. Sun, Int. J. Biol. Macromol., 2017, 97, 447-459.

35 J. L. Wen, S. N. Sun, T. Q. Yuan, F. Xu and R. C. Sun, Bioresour. Technol., 2013, 150, 278-286.

36 F. Abdelkafi, H. Ammar, B. Rousseau, M. Tessier, G. R. El and A. Fradet, Biomacromolecules, 2011, 12, 3895-3902.

37 J. L. Wen, S. L. Sun, B. L. Xue and R. C. Sun, Materials, 2013, 6, 359-391.

38 P. F. van Bergen, I. Poole, T. M. A. Ogilvie, C. Caple and R. P. Evershed, Rapid Commun. Mass Spectrom., 2000, 14, 71-79.

39 T. Dizhbite, G. Telysheva, V. Jurkjane and U. Viesturs, Bioresour. Technol., 2004, 95, 309-317.

40 A. García, A. Toledano, M. Á. Andrés and J. Labidi, Process Biochem., 2010, 45, 935-940.

41 M. F. Li, S. N. Sun, F. Xu and R. C. Sun, Food Chem., 2012, 134, 1392-1398.

42 J. Ponomarenko, T. Dizhbite, M. Lauberts, A. Volperts, G. Dobele and G. Telysheva, J. Anal. Appl. Pyrolysis, 2015, 113, 360-369.

43 M. P. Vinardell, V. Ugartondo and M. Mitjans, Ind. Crops Prod., 2008, 27, 220-223.

44 F. J. Lu, L. H. Chu and R. J. Gau, Nutr. Cancer, 1998, 30, 3138. 